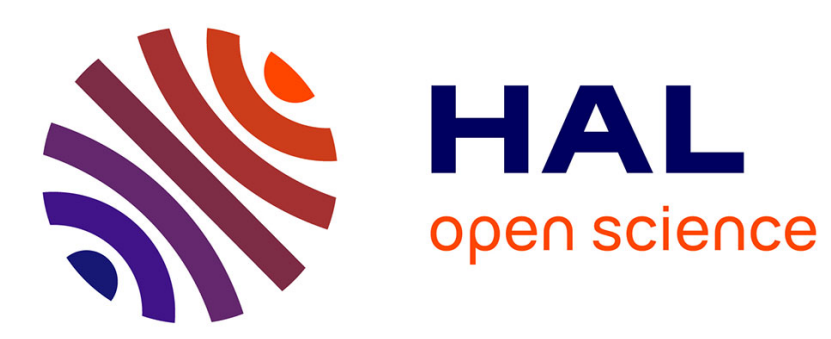

\title{
Steady state macroscopic model of the influence of water on the performances of a micro air-breathing fuel cell
}

\author{
M. Zeidan, Ch. Turpin, F. Cantin, Stéphan Astier
}

\section{To cite this version:}

M. Zeidan, Ch. Turpin, F. Cantin, Stéphan Astier. Steady state macroscopic model of the influence of water on the performances of a micro air-breathing fuel cell. European Physical Journal: Applied Physics, 2011, 54 (2), pp.23406. 10.1051/epjap/2011100269 . hal-00702654

\section{HAL Id: hal-00702654 \\ https://hal.science/hal-00702654}

Submitted on 31 May 2012

HAL is a multi-disciplinary open access archive for the deposit and dissemination of scientific research documents, whether they are published or not. The documents may come from teaching and research institutions in France or abroad, or from public or private research centers.
L'archive ouverte pluridisciplinaire HAL, est destinée au dépôt et à la diffusion de documents scientifiques de niveau recherche, publiés ou non, émanant des établissements d'enseignement et de recherche français ou étrangers, des laboratoires publics ou privés. 


\title{
Steady state macroscopic model of the influence of water on the performances of a micro air-breathing fuel cell
}

\author{
Marwan Zeidan ${ }^{1}$, Christophe Turpin ${ }^{2, a}$, Frédéric Cantin ${ }^{3}$, Stéphan Astier ${ }^{4}$ \\ ${ }^{1}$ Ph.D. Student, Graduate ENSEEIHT (Ecole Nationale Supérieure d'Electrotechnique, d'Electronique, d'Hydraulique, et des \\ Télécommunications), Laboratoire LAPLACE (Laboratoire PLAsma et Conversion d'Energie), 2, rue Charles Camichel BP 7122. \\ 31071 Toulouse Cedex 7, France \\ 2 Full Researcher, CNRS, Laboratoire LAPLACE \\ ${ }^{3}$ Engineer at STMicroelectronics, Industrial supervisor, 16 Rue Pierre et Marie Curie 37100 Tours, France \\ ${ }^{4}$ Professor, ENSEEIHT-INPT, Laboratoire LAPLACE \\ a Email address: turpin@laplace.univ-tlse.fr
}

Model of the influence of water on a micro air-breathing fuel cell

\begin{abstract}
Water management is one of the most crucial issues to drive PEM fuel cells. The challenge is enhanced in the case of Micro Air-Breathing Proton Exchange Membrane Fuel Cells ( $\mu A B F C)$ : their thinness and their reduced surface indeed make their hydration state fast changing and very sensitive to the experimental conditions (temperature and Relative Humidity $(R H)$ ). It can lead to strong flooding or drying out issues. Firstly, this study highlights this sensitivity by various measurements. Then a steady state macroscopic model for the $\mu$ ABFC is proposed, focusing on the cathode, using a rather original approach for diffusion in porous media. Finally, a literal steady state formula for the water content is provided, and its influences on the performances of the $\mu \mathrm{ABFC}$ are explicitly proposed. The model is parameterized and compared to measures in several atmospheric conditions.
\end{abstract}

\section{Introduction}

\subsection{General issues}

PEM fuel cells produce water coming from the cathodic $\mathrm{O}_{2}$ reduction. This water can accumulate in the porous medium of the cathode in a mixture of liquid and gaseous phases, like illustrated in [1], depending on the operating conditions. As an example, Qiangu Yan et al. show in [2] the strong impact of the $R H / T$ of the feeding gases. In general, this water is evacuated by evaporation toward the atmosphere in the case of air-breathing fuel cells [3], or is carried by the cathodic air/ $\mathrm{O}_{2}$ overflow [4]. Many studies focus on what happens in the cathode, through various twophase models [4-7], sometimes modelling the porous medium's geometry [1], taking into account the permeability, the porosity, and the wettability of the electrode [5,8-9], and dealing with the interfacial issues that multi layers electrodes can raise [1,10-11]. It involves complex mass transport, and energy balances, that can be carried out at different scales, from a macroscopic $[9,12]$ to a microscopic point of view $[9,13-14]$.

Water can also diffuse back through the membrane toward the anode, hydrating or dehydrating the membrane [1516]. The protonic conduction also drags water from the anode to the cathode, more or less compensating for the back diffusion. Moreover, the membrane is generally made of Nafion, which also partly constitutes the electrodes. This polymer can accumulate and restore water in a non linear way (Schroeder paradox for example), strongly depending on the activity and quantity of water at its surface, that is to say the pore water (the liquid water in the pores of the porous medium) in the membrane and in the electrodes. The hydric events located in the membrane are very complex, and are the core of a lot of dedicated studies, like [18] or [19]. Complex theories, through capillarity models, try to explain the Schroeder paradox that can occur in membranes [17].

All those phenomena, interacting with each other, depending on operating conditions, are the heart of the fuel cell's performances.

Indeed, PEMFCs need to be hydrated, mostly to allow $\mathrm{H}^{+}$diffusion/conduction from the anodic active sites to the cathodic ones: a dry fuel cell will not start, or it will have very low performances; it needs to be hydrated first. Qianpu Wang et al. propose a description of the impact of water on this phenomenon in [7]. Nevertheless, exceeding water can have a clogging/flooding effect because gases, mostly $\mathrm{O}_{2}$, need to diffuse correctly toward the active $\mathrm{Pt}$ conglomerates that are distributed in the electrodes, in order to make the electrochemical reaction possible. The influence of water on $\mathrm{O}_{2}$ diffusion can be observed through the pressure drop measurement technique, as studied in [20-21]. Other methods, aiming at observing in situ water behaviour, can also give a qualitative idea of the impact that water can have on $\mathrm{O}_{2}$ diffusion: visual measurements on transparent fuel cells as seen in [22-23], or neutron radiology [24-25]. St-Pierre gives in [26] an exhaustive list of the experimental methods that can be used for this purpose. The influence of water on $\mathrm{O}_{2}$ diffusion is thus modelled in numerous ways $[9,11,27]$. However, not only the paths to those active sites need to be diffusion-friendly. The Pt conglomerates themselves also need to fulfil the triple phase boundary (TPB): it needs to be hydrated enough to allow $\mathrm{H}^{+}$arrival/departure through the neighbouring Nafion or through the pore water, but not too much, for gaseous $\mathrm{O}_{2}$ adsorption issues. This possible inerting of the active sites can be taken into account through a water content depending coverage/efficiency coefficient, cutting the active surface down in several ways, as illustrated in $[4,5,9,28]$. Finally, between the two extreme situations that drying out and flooding are, liquid water presence has a first order influence on every physical (diffusions and conduction) and electrochemical (activation) phenomenon. Water management thus consists in controlling the operating conditions to 
find the best compromise (between drying out and flooding) to get the best performances for the PEMFC.

Nevertheless, all the phenomena described above are linked in a non linear and globally non monotone way: a proton-friendly hydric situation can be hostile to $\mathrm{O}_{2}$, those two species having antagonist hydric needs. Thus it is quite hard to get the best fuel cell's working point 'manually' and empirically. This becomes nearly impossible in the case of the micro air-breathing fuel cells $(\mu \mathrm{ABFC})$ we deal with in this article. $\mathrm{N}$. Karst studied them and enlightened these water-linked difficulties in [29-30]. We will describe them precisely in the following, concluding that $\mu$ ABFC's geometrical and technological features make them very sensitive to any atmospheric conditions and operating temperature change. Moreover those parameters will vary during the final use of those $\mu A B F C$; they are indeed intended for a non hermetic portable device that is supposed to operate everywhere in the world as a range extender for lithium-ion batteries of a cell phone.

In conclusion, a model is strongly needed to estimate the water content of the fuel cell first, and then to describe its influences on the PEMFC's electrical performances. The final goal is to be able to optimize online the $\mu A B F C$ 's environment, thanks to its auxiliaries. The part 2 of this paper focuses on the first aspect of the problem: the calculation of the water content according to the atmospheric conditions and the fuel cell's temperature. The links with the physic-chemical model of the fuel cell will be proposed in the part 3, leading to a micro fuel cell model depending on atmospheric conditions. The whole study is achieved in the steady state case.

\section{2 $\mu \mathrm{ABFC}$ description and application}

The geometric and technological features of the $\mu$ ABFCs are very specific and will strongly impact the choices we will make for the hydric model. The studied $\mu$ ABFCs are made in France at STMicroelectronics and at the CEA Liten, by successive depositions of thin layers on a pre-etched silicon substrate (for hydrogen feeding). Both anode and cathode active layers are deposited by ink-jet printing, and are respectively $10 \mu \mathrm{m}$ and $20 \mu \mathrm{m}$ thick. The membrane is thicker $(30 \mu \mathrm{m})$ and is coated on the anode. To obtain the cathodic collector, a very thin $(0.5 \mu \mathrm{m})$ gold layer is deposited on the top of the cathode. It is both thin and porous enough to allow air-breathing and water evacuation, but it is homogeneous enough to enable a good electrical contact. To get more precisions on this process, please refer to [29]. A schematic cross-section of the micro-PEMFC is shown in Fig.2. There are no purely non-active gas diffusion layers (GDL), due to process limitations. This significant difference with most of the classically studied fuel cells will have an impact on the model: contrary to what Yun Wang et al. do in [10-11] for example, we will not have to link two different diffusion media for the $\mathrm{H}_{2} \mathrm{O}$ electrode diffusion. The geometric surface of the cell is about $1 \mathrm{~cm}^{2}$, which is very small regarding to the commonly modelled fuel cells, for which a small surface is usually not less than $20 \mathrm{~cm}^{2}$. Instead of using surface currents in the following, we will rather use the global current actually crossing the fuel cell, considering, for a first estimation, a homogeneous current repartition in the electrodes. This hypothesis is strengthened by the fact that both anodic and cathodic current collections are shared out between 3 gold contacts each (Fig.1), which contributes to a better current repartition.

Those small dimensions and the absence of a GDL make these fuel cells highly sensitive to atmospheric changes, as well with regard to its $R H$, temperature, or turbulences.

Those $\mu A B F C$ s aim at reaching $1 \mathrm{~W} / \mathrm{cm}^{2}$. They are designed to be mounted in an active packaging, more or less opened to the ambient air and in which atmospheric conditions will be driven by the fuel cell's water production and temperature, which are themselves depending on atmospheric conditions. Micro built-in fans will be used to manage those environmental variables. In the studies we carried out, and the measures we used to develop our model, the $\mu A B F C$ was opened to a fully controlled atmosphere, mounted on a specific measurement equipment; we indeed wanted to model the $\mu A B F C$ itself, separated from its packaging's influence.

\section{Calculation of the water content within the porous cathode according to the experimental conditions and the working current point}

\subsection{Water content model description}

\subsubsection{Global description and main hypotheses}

\section{Cathode focus:}

Numerous studies have been devoted to developing mathematical models for the transport of reactants and produced water in PEMFC. They sometimes deal with global balances, taking into account the hydric interactions between the gas channels, the membrane and the two electrodes, and modelling water transport and transformation in each of these media, like Springer et al. in [31], or like in [8,37]. Nevertheless, authors often focus on modelling the electrodes hydric behaviour, and especially the cathode [5-7,9,22]. Indeed, this is first of all where water is produced; this is the source location for mostly every hydric issue. Secondly, the cathode is the electrode where $\mathrm{O}_{2}$ is reduced. It is commonly admitted that $\mathrm{O}_{2}$ diffusion is more problematic than the $\mathrm{H}_{2}$ one, due to the fact that $\mathrm{O}_{2}$ is a bigger molecule than $\mathrm{H}_{2}$. In fact $\mathrm{H}_{2}$ diffusion is often neglected [7]. The cathode thus is where liquid water presence will have the greater impact.

Moreover, in our approach, the complex impact of the membrane's hydration will not be explicitly modelled, as well as it is done in a lot of studies. The membrane resistance will be indeed estimated (Fig.4) starting from Electrochemical Impedance Spectroscopy (EIS) measurements that were carried out along the polarization curve. In these studies concentrated on membrane modelling, the anode is considered to be ideally hydrated; in these conditions, the $\mathrm{H}_{2}$ has no problem to reach the active sites $\left(\mathrm{H}_{2}\right.$ diffusion neglected), and the produced $\mathrm{H}^{+}$have no problem to reach the membrane (no anodic drying out issues). To take into account the flow of water leaving/reaching the cathode toward/from the membrane, a net transport coefficient is often used, modifying the produced water flow $[2,4]$. We 
neglected this coefficient here, for the same reason [10] exposes. Moreover, the multi-conditions electrical measurements we used to calibrate our model were performed by Nicolas Karst at the CEA Liten. They are displayed in Fig.5 and in Fig.6. N. Karst proved in [30] that in the conditions the tests were carried out, the anode was not suffering from dehydration, which strengthens our cathode focus.

Model scale:

Microscopic points of view are often preferred to develop cathodic hydric models. Nevertheless, macroscopic-like models can be sometimes used, like the segmented approach of Yong-Song Chen et al. in [32], or the average approach of Cecile Gondrand in [33] also adopted by Prodip K. Das in [9].

Here, we will chose a global macroscopic scale. We will consider macroscopic parameters and variables (the water content for instance will be uniform in the whole cathode), that will not be precisely located in the fuel cell, but that will be representative of the global cathodic situation.

\section{Classical Fickian diffusion:}

Generally, cathodic water transport models deal with multicomponent diffusion, using Stefan-Maxwell equations $[32,33]$, and Darcy transport equations, taking into account the porosity of the medium in several ways. This leads to binary $\left(\mathrm{O}_{2}\right.$ and $\left.\mathrm{H}_{2} \mathrm{O}\right)$ and sometimes ternary $\left(\mathrm{O}_{2}, \mathrm{~N}_{2}\right.$, and $\left.\mathrm{H}_{2} \mathrm{O}\right)$ systems. Nevertheless, Cecile Gondrand showed in [33] that the generalised Fickian crossed coefficients could be neglected, leading to a classical Fickian behaviour. We propose to consider separately gaseous $\mathrm{H}_{2} \mathrm{O}$ and $\mathrm{O}_{2}$ diffusion: the water content will be calculated from the purely hydric study we will carry in the part 2, and then the effect of this water content will be included in $\mathrm{O}_{2}$ diffusion.

\section{Phase of the water:}

Almost all the hydric models in the literature only suppose gaseous water in the cathode, considering that water is produced in this phase. Regarding the conditions, and/or above a critical current value, the vapour pressure reaches a saturation value, making liquid water appear, which leads to a two-phase mode $[4,5,20 \ldots]$.

Our $\mu A B F C$ operating at low temperatures $\left(45^{\circ} \mathrm{C}\right.$ max), the produced water will be supposed liquid (generally there is always at least an equilibrated liquid drop somewhere in the porous medium). Moreover, the fuel cell itself is opened to the atmosphere: its cathode will be in contact with an air volume proportionally large compared with a classical closed fuel cell. In this case, the liquefaction of vapour will be more limited than it is in a closed confined cathode. Consequently, our model does not work with two modes (one phase/two phases). Its core is the calculation of the vapour flow that is evacuated from the fuel cell by evaporation. In steady state, there will be a balance between the evaporated and the produced water. If this balance is not assured, there will be progressively flooding or drying out.

\section{Other hypotheses:}

We will consider that the system is under steady state. Each gas is considered like a perfect gas. We neglect the influence of the diffusion of the dissolved $\mathrm{O}_{2}$. The temperature $T_{F C}$ is uniform within the whole $\mu$ ABFC.

\subsubsection{The hydric balance}

We aim at calculating the water content of the $\mu A B F C$ 's cathode, defined by the water saturation $s$. The saturation is the ratio between the volume of the pores that are occupied by liquid water, and the total pore volume that is theoretically available:

$$
s=\frac{V_{l i q u}}{V_{t o t}}
$$

Eq.2 proposes the 'purely hydric' balance that comes from the hypotheses exposed in 2.1.1:

$$
n_{\mathrm{H}_{2} \mathrm{O}}(t+d t)=n_{\mathrm{H}_{2} \mathrm{O}}(t)+J_{\mathrm{H}_{2} \mathrm{O}}^{\text {prod }}(t) \cdot d t-J_{\mathrm{H}_{2} \mathrm{O}}^{\text {evap }}(t) \cdot d t
$$

Where $J_{\mathrm{H}_{2} \mathrm{O}}^{\text {prod }}$ and $J_{\mathrm{H}_{2} \mathrm{O}}^{\text {evap }}$ are respectively the produced and the evaporated water molar flows. As the $\mu \mathrm{ABFC}$ is supposed to be under steady state, this becomes:

$$
J_{H_{2} \mathrm{O}}^{\text {evap }}(s)=J_{H_{2} \mathrm{O}}^{\text {prod }}=\frac{I_{F C}}{2 F}
$$

We now want to express $J_{H_{2} O}^{\text {evap }}(s)$ literally, in order to know $s$.

For that purpose, we consider that, in the porous medium of the cathode, only the vapour concentration difference between the inner liquid water's surface and the outside surface of the cathode leads to the evaporation of the liquid water to the atmosphere. We stated in 2.1.1 that this diffusion was Fickian:

$$
J_{\mathrm{H}_{2} \mathrm{O}}^{\text {evap }}=\frac{D_{\mathrm{H}_{2} \mathrm{O}}^{\text {eff }} \cdot S_{\text {evap }}}{\delta_{\text {evap }}} \cdot \Delta C_{\mathrm{H}_{2} \mathrm{O}}
$$


Where $S_{\text {evap }}$ is the surface through which the vapour diffusion occurs, $\delta_{\text {evap }}$ is the diffusive length, and $D_{H_{2} O}^{\text {eff }}$ is the effective diffusivity of gaseous water through air, in a partially liquid-saturated porous medium. $\Delta C_{\mathrm{H}_{2} \mathrm{O}}$ is the difference between the water concentration at the surface of the inner pore liquid water $C_{\mathrm{H}_{2} \mathrm{O}}^{\mathrm{in}}$ and the water concentration there is at the surface of the cathode $C_{\mathrm{H}_{2} \mathrm{O}}^{\text {surf }}$ :

$$
\Delta C_{\mathrm{H}_{2} \mathrm{O}}=C_{\mathrm{H}_{2} \mathrm{O}}^{\text {in }}-C_{\mathrm{H}_{2} \mathrm{O}}^{\text {surf }}
$$

\subsection{Calculation of vapour concentrations}

2.2.1 Calculation of $\mathrm{C}_{\mathrm{H}_{2} \mathrm{O}}^{\text {in }}$

In porous media, the equilibrated vapour pressure at the interface with liquid water is not rigorously equal to the saturated value it would have in a free medium. This equilibrium pressure is theoretically modified by the capillaritylinked phenomena that are involved by the porosity of the medium. A common formalisation is given by the capillary condensation theory, through the Kelvin equation, which is for example used by Cecile Gondrand in [33]. In this case, the saturation pressure of vapour is affected by the capillary pressure $P_{c}$ :

$$
P_{H_{2} \mathrm{O}, v}=P_{H_{2} \mathrm{O}, v}^{s a t}(T) e^{\frac{P_{c}(s) M_{\mathrm{H}_{2} \mathrm{O}}}{\rho_{\mathrm{H}_{2}, l} R T}}
$$

Where $P_{c}(s)$ depends on $s$ through the Levrett function [5].

A numerical application shows that in every situation, the exponential term of Eq.6 is very close to 1 (in extreme cases, between 0.8 and 1.2). That is why we assume in the following that we are in a classical situation:

$$
C_{H_{2} O}^{i n}=C_{H_{2} O}^{s a t}\left(T_{F C}\right)=\frac{P_{H_{2} O}^{s a t}}{R T_{F C}}
$$

\subsubsection{Calculation of $C_{\mathrm{H}_{2} \mathrm{O}}^{\text {surf }}$}

$\mathrm{C}_{\mathrm{H}_{2} \mathrm{O}}^{\text {surf }}$ depends on the flow of gaseous water that gets out of the fuel cell at the interface between the cathode surface and the atmosphere, and on the atmospheric conditions $\left(R H_{a}, T_{a}\right)$ that are set "far from" the cathode surface, by the climatic chamber. Indeed, $\mathrm{H}_{2} \mathrm{O}_{v}^{\text {surf }}$ will have to undergo a mass transfer in the atmosphere, driven by diffusion and possibly natural convection, which is due to a possible temperature gradient between the $\mu$ ABFC's surface and the external atmosphere temperature. We propose, for this first macroscopic approach, to describe the diffusion/convection phenomenon by a simple resistance of mass transfer $R_{D C}$, representing the parallel influence of steady state diffusion and natural convection:

$$
R_{D C}=\frac{1}{\frac{1}{R_{d i f f}^{a}}+\frac{1}{R_{c o n v}^{a}}}
$$

With this variable, we can calculate $C_{\mathrm{H}_{2} \mathrm{O}}^{\text {sur }}$, as we know the $\mathrm{H}_{2} \mathrm{O}$ flow at the interface, thanks to Eq.3:

$$
C_{\mathrm{H}_{2} \mathrm{O}}^{\text {surf }}=C_{\mathrm{H}_{2} \mathrm{O}}^{\infty}+R_{D C} \frac{I_{F C}}{2 F}
$$

Where, according to the definition of relative humidity:

$$
C_{H_{2} \mathrm{O}}^{\infty}=\frac{R H_{a} P_{\text {sat }}\left(T_{a}\right)}{R T_{a}}
$$

We can in the same way calculate the surface concentration of $\mathrm{O}_{2}$, using the same $R_{D C}$ :

$$
C_{O_{2}}^{\text {surf }}=C_{O_{2}}^{\infty}-R_{D C} \frac{I_{F C}}{4 F}
$$

We now need to estimate $R_{D C}$, that is to say $R_{\text {diff }}^{a}$ and $R_{\text {conv }}^{a}$.

Calculation of $R_{\text {diff }}^{a}$ : 
$R_{\text {diff }}^{a}$ comes from a steady state Fickian description of diffusion in the atmosphere:

$$
R_{\text {diff }}^{a}=\frac{\delta_{\text {carac }}}{S_{\text {carac }} D_{\mathrm{H}_{2} \mathrm{O}_{,}, 0}}
$$

In the whole study, to take into account the variations of diffusivity with temperature, we used a common correlation [11]:

$$
D_{X}=D_{X, 0}\left(\frac{T}{298}\right)^{1.5}
$$

Where $T$ is the temperature of the medium the diffusion takes place in.

Thus, the diffusion resistance is finally given by:

$$
R_{\text {diff }}^{a}=\frac{R_{\text {diff }, 0}^{a}}{\left(\frac{\langle T\rangle}{298}\right)^{1.5}}
$$

Where:

$$
\langle T\rangle=\frac{T_{F C}+T_{a}}{2}
$$

And where $R_{d i f f, 0}^{a}$ is the $298 \mathrm{~K}$ reference. Eq. 15 represents the average temperature of the air between the surface of the cathode and the point of space where $R H_{a i r}=R H_{a}$ and $T_{a i r}=T_{a}$.

Calculation of $R_{\text {conv }}^{a}$ :

Concerning the convection resistance, we suppose that it depends on temperature through the following relation:

$$
R_{\text {conv }}^{a}=\frac{1}{\chi}\left(\frac{\Delta T}{\langle T\rangle}\right)^{-0.25}
$$

Where:

$$
\Delta T=T_{F C}-T_{a}
$$

We propose in fact this relation by analogy with thermal convection.

Mixing Eq.8, 14 and 16 leads to Eq.18:

$$
R_{D C}=\frac{1}{\frac{1}{R_{d i f f, 0}^{a}}\left(\frac{\langle T\rangle}{298}\right)^{1.5}+\chi\left(\frac{\Delta T}{\langle T\rangle}\right)^{0.25}}
$$

At this point, we are able to calculate $\Delta C_{H_{2} O}$.

\subsection{Influence of $s$ on the evaporated flow}

\subsubsection{Dependency of $D_{\mathrm{H}_{2} \mathrm{O}}^{\text {eff }}$ on $\mathrm{s}$}

There are a lot of ways to take into account the porous nature of the medium a diffusion mechanism occurs in, especially when it is partially saturated with liquid water. The most common way is to impact the effective diffusivity of the species that diffuses through the pores, through the Bruggeman formula:

$$
D_{X}^{e f f}=\varepsilon^{a_{X}}(1-s)^{b_{X}} D_{X}
$$

Where $D_{X}$ is the "free" diffusivity of the species $X$ through air at the operating temperature, out of the porous medium. In this formula, the more liquid water there is in the pores, the more tortuous the path the diffusing gas will have to take will be, the weaker its diffusivity will be. The parameters $a_{X}$ and $b_{X}$ are often equal and are called tortuosity. Nevertheless, [40] deals with the theory of porous media diffusion, and gives another definition for tortuosity, that we will use in the following (this is just a vocabulary matter):

$$
\tau=\frac{D_{X}^{e f f}}{D_{X}}
$$

The most commonly found case for parameterization is $a_{X}=b_{X}=1.5$. Nevertheless, in some studies, $a_{X} \neq b_{X}$, and other values than 1.5 are sometimes used. We propose to sum up some of these cases in Tab.1, focusing on the most important parameter $b_{X}$. 
There are also other methods to make the effective diffusivity depend on $s$, as described in [40]. Regarding the diversity of parameters we can find, we will use $a_{X}$ and $b_{X}$ as adjustable parameters in our model:

$$
D_{\mathrm{H}_{2} \mathrm{O}}^{\text {eff }}=\varepsilon^{a_{\mathrm{H}_{2} \mathrm{O}}}(1-s)^{b_{\mathrm{H}_{2} \mathrm{O}}} D_{\mathrm{H}_{2} \mathrm{O}}
$$

With, according to Eq.13:

$$
D_{\mathrm{H}_{2} \mathrm{O}}=D_{\mathrm{H}_{2} \mathrm{O}, 0}\left(\frac{T_{F C}}{298}\right)^{1.5}
$$

\subsubsection{Dependency of $S_{\text {evap }}$ and $\delta_{\text {evap }}$ on $s$}

Other studies are devoted to developing other approaches for evaporation in porous media. Those studies are often more focused on porous materials or powders drying processes, and are not dealing with fuel cells. For example, in [34], F. Debaste proposes various evaporation models, at an Representative Elementary Volume (REV) scale, in which he takes into account the variation of the evaporation surface, or of the vapour diffusion length, with the water content, modelling the physiognomy of water in pores.

Our model is inspired by such methods, and by the Bruggeman type formulations.

We will consider that a small cathodic water content $s$ involves a small evaporating surface, which one will increase when $s$ does. This is traduced by:

$$
S_{\text {evap }}=s^{b_{H_{2} O} O} S_{K}
$$

Where $S_{K}$ is the geometric surface of the cathode.

In the same way, we will consider that macroscopically, the more liquid water there will be in the pores, the shorter the average path the vapour will have to take will be, the complexity of this path being taken into account by the tortuosity in Eq.21:

$$
\delta_{\text {evap }}=(1-s)^{b_{H_{2} O}} \delta_{K}
$$

This way, we could see $b_{H_{2} \mathrm{O}}$ as being an image of the sensibility of the gaseous water diffusion phenomenon to the presence of liquid water in the porous medium where it takes place. We will see in the following that we will reproduce this definition on every diffusive species.

This approach is quite original, and its relevance will be proven in the final model in the following.

\subsection{Literal $s$ calculation}

Finally, according to Eq.4, 21,23 and 24 we have:

This leads, using Eq.3, to:

$$
J_{\mathrm{H}_{2} \mathrm{O}}^{\text {prod }}=\frac{\varepsilon^{a_{\mathrm{H}_{2} \mathrm{O}}}(1-s)^{b_{\mathrm{H}_{2} \mathrm{O}}} D_{\mathrm{H}_{2} \mathrm{O}} \cdot s^{b_{\mathrm{H}_{2} \mathrm{O}}} S_{K}}{(1-s)^{b_{\mathrm{H}_{2} \mathrm{O}}} \delta_{K}} \cdot \Delta C_{\mathrm{H}_{2} \mathrm{O}}
$$

$$
s=\left(\frac{I_{F C}}{2 F \Delta C_{H_{2} O} \frac{\varepsilon^{a_{H_{2}} \mathrm{O}} \cdot D_{\mathrm{H}_{2} \mathrm{O}} \cdot S_{K}}{\delta_{K}}}\right)^{\frac{1}{b_{H_{2} O}}}
$$

Eq.26 gives a literal expression of $s$, the steady state water content of the cathode, depending on the operation conditions $R H_{a}, T_{a}$ and $T_{F C}(E q .7,9,10)$ and on the operation current point $I_{F C}$. To illustrate this dependency, we displayed the $s$ curves in Fig. 3 for the experimental conditions (Tab.3) that N. Karst applied in [30] for the measurements.

This plot uses the model parameters of the Tab.4. We can notice that s values are coherent with the experimental conditions: the dryer the atmosphere is, the lower the water content is.

\section{Steady state macroscopic modelling of the $\mu A B F C$ performances according to the cathodic water content}

\subsection{The theoretical classic fuel cell model}

\subsubsection{The classical model}

The theoretical reversible fuel cell potential is given by Nernst's relation:

$$
V_{\mathrm{Rev}}=-\frac{\Delta G^{0}}{2 F}+\frac{R T_{F C}}{2 F} \ln \left(P_{H_{2}} P_{O_{2}}^{0.5}\right)
$$

But, when the current increases, the fuel cell voltage progressively drops due to physical losses. 
In steady state $\left(I=I_{a c t}\right.$ ), the activation current is described by the Butler-Volmer equation, expressed with the Tafel approximation $\left(I_{a c t}>>I_{0}\right)$ by:

$$
I_{a c t}=I=I_{0}\left(\frac{C_{O_{2}}}{C_{O_{2}}^{r e f}}\right)^{\gamma_{o_{2}}}\left(\frac{C_{H^{+}}}{C_{H^{+}}^{r e f}}\right)^{\gamma_{u^{+}}} \exp \left(\frac{2 \alpha F}{R T_{F C}} \eta\right)
$$

As our water content is set by the imposed $I_{F C}$ (Eq.26), we reverse this relation:

$$
\eta=\frac{R T_{F C}}{2 \alpha F} \ln \left(\frac{I}{I_{0}}\right)-\frac{R T_{F C}}{2 \frac{\alpha}{\gamma_{O_{2}}} F} \ln \left(\frac{C_{O_{2}}}{C_{O_{2}}^{r e f}}\right)-\frac{R T_{F C}}{2 \frac{\alpha}{\gamma_{H^{+}}} F} \ln \left(\frac{C_{H^{+}}}{C_{H^{+}}^{r e f}}\right)
$$

After having solved linear Fickian diffusion equations to express the species' concentrations, the voltage drop due to activation and diffusion phenomena is:

$$
\eta=\frac{R T_{F C}}{2 \alpha F} \ln \left(\frac{I}{I_{0}}\right)-\frac{R T_{F C}}{2 \frac{\alpha}{\gamma_{O_{2}}} F} \ln \left(1-\frac{I}{I_{\mathrm{lim}}^{O_{2}}}\right)-\frac{R T_{F C}}{2 \frac{\alpha}{\gamma_{H^{\prime}}} F} \ln \left(1-\frac{I}{I_{\mathrm{lim}}^{H^{\prime}}}\right)
$$

Where

$$
I_{\lim }^{X}=n F S_{\text {diff }}^{X} \frac{D_{X}^{e f f}}{\delta_{d i f f}^{X}} C_{X}^{r e f}
$$

We also set, as a new parameter:

$$
\beta_{X}=\frac{\alpha}{\gamma_{X}}
$$

One can notice in Eq.30 that we considered only pure diffusion for $\mathrm{H}^{+}$, using Fick's Law, contrary to what is often done $[7,35]$. Indeed, we consider that the migration part of the protons' diffusive mechanism is already taken into account by the variations of the global electric resistance $R_{\text {elec }}$ we extracted from the EIS carried out at the end of each working point. As a matter of fact, $R_{e l e c}$ is the sum of the electronic resistance and the protonic one, which contains the information of the conductivity of the Nafion that constitutes the membrane and the electrodes. Moreover, for this model, we only took into account the pore water protonic diffusion that occurs in the cathode.

We can now express each loss separately.

Activation losses:

$$
\eta_{a c t}=\frac{R T_{F C}}{2 \alpha F} \ln \left(\frac{I+I_{n}}{I_{0}}\right)
$$

Where $\mathrm{I}_{0}$ depends on temperature, following this relation $[11,28]$ :

$$
I_{0}=I_{0}^{\max } e^{-\frac{73269}{R}\left(\frac{1}{T_{F C}}-\frac{1}{353.15}\right)}
$$

We added a leak current $I_{n}$, which is a simple and common way to take into account $\mathrm{H}_{2}$ crossover issues, like M.G. Santarelli does in [12].

Diffusion losses:

$$
\eta_{\text {diff }}^{X}=\frac{R T_{F C}}{2 \beta_{X} F} \ln \left(1-\frac{I+I_{n}}{I_{\text {lim }}^{X}}\right)
$$

Ohmic losses:

$$
\eta_{\text {elec }}=R_{\text {elec }}\left(I+I_{n}\right)
$$

Where $R_{e l e c}$ varies with $I_{F C}$ and is a measured data (Fig.4).

The global steady state model is finally given by :

$$
V_{F C}=V_{\text {rev }}-\eta_{a c t}-\sum\left|\eta_{\text {diff }}\right|-\eta_{\text {elec }}
$$

\subsection{Influence of $s$ in the model}

The parameters that are supposed to be the most dependent on water are diffusion parameters, and activation parameters.

\subsection{1 $\mathrm{O}_{2}$ diffusion}


Oxygen diffusion mechanism will undergo the same type of liquid water influence that vapour does, through

$$
I_{\text {lim }}^{\mathrm{O}_{2}}=2 F S_{\text {diff }}^{\mathrm{O}_{2}} \frac{D_{\mathrm{O}_{2}}^{\text {eff }}}{\delta_{\text {diff }}^{O_{2}}} C_{O_{2}}^{\text {surf }}
$$

$D_{H_{0}}^{\text {eff }}$ : The more liquid water there will be in the porous medium, the more tortuous the path from the cathode surface to the active sites will be for $\mathrm{O}_{2}$, the smaller the effective diffusivity will be.

$$
D_{O_{2}}^{e f f}=\varepsilon^{a_{O_{2}}}(1-s)^{b_{O_{2}}} \cdot D_{O_{2}}
$$

$S_{\text {diff }}^{O_{2}}:$ The more liquid water there will be in the pores, the smaller the average surface through which $\mathrm{O}_{2}$ diffuses will be:

$$
S_{\text {diff }}^{O_{2}}=(1-s)^{b_{O_{2}}} \cdot S_{K}
$$

$\delta_{\text {diff }}^{o_{2}}:$ The more liquid water there will be in the pores, the shorter the average path the $\mathrm{O}_{2}$ will have to take will be:

$$
\delta_{\text {diff }}^{O_{2}}=(1-s)^{b_{O_{2}}} \cdot \delta_{K}
$$

Mixing Eq.38, 39, 40 and 41 leads to:

$$
I_{\lim }^{O_{2}}=2 F \varepsilon^{a_{O_{2}}} \frac{S_{K} D_{O_{2}}}{\delta_{K}}(1-s)^{b_{O_{2}}} C_{O_{2}}^{\text {surf }}
$$

\subsection{2 $\mathrm{H}^{+}$diffusion}

$\mathrm{H}^{+}$diffusion probably occurs very locally, on very short distances. We can thus assume that the protonic effective diffusivity is not very sensitive to the water content:

$$
D_{H^{+}}^{e f f}=\varepsilon^{a H^{+}} \cdot D_{H^{+}}
$$

$S_{\text {diff }}^{H^{+}}$: The more liquid water there will be in the pores, the higher the average surface through which $\mathrm{H}^{+}$diffuses will be:

$$
S_{\text {diff }}^{H^{+}}=S^{b}{ }^{H^{+}} \cdot S_{K}
$$

$\delta_{d i f f}^{H^{+}}$: The more liquid water there will be in the pores, the lower the average path the $\mathrm{H}^{+}$will have to take will be:

$$
\delta_{\text {diff }}^{H^{+}}=(1-s)^{b_{H^{+}}} \cdot \delta_{K}
$$

Mixing Eq.31,43,44 and 45 leads to:

$$
I_{\lim }^{H^{+}}=F \varepsilon^{a}{ }^{H^{+}} \frac{S_{K} D_{H^{+}}}{\delta_{K}}\left(\frac{s}{1-s}\right)^{b} C_{H^{+}}^{r e f}
$$

Like described by Eq.13, we take into account the dependence of the diffusivities of $\mathrm{H}^{+}$and $\mathrm{O}_{2}$ to temperature:

and

$$
D_{\mathrm{O}_{2}}=D_{\mathrm{O}_{2}, 0}\left(\frac{T_{F C}}{298}\right)^{1.5}
$$

$$
D_{H^{+}}=D_{H^{+}, 0}\left(\frac{T_{F C}}{298}\right)^{1.5}
$$

For each steady state measured point, an explicit water content was expressed. Laws for the dependence on this liquid saturation were proposed for $V_{F C}$. In the next part, we will parameterize this model starting from several measurements. The model parameters that have to be identified are gathered in Tab.2.

\section{Measurements and model results}

Our final goal is to match our model with an unique set of the Tab.2 parameters with 8 polarization U-I curves, that were measured in 8 different experimental conditions, that we will express through this notation in the following, for readability: $\left[R H_{a}, T_{a}=T_{F C}^{t h}\right.$ ]. We will describe them in the following (Fig.5 and Fig.6). By "unique", we mean that ideally, one only set of optimized parameters should be able to reproduce the $\mu$ ABFC's behaviour for 8 different experimental conditions, independently from those conditions. This is very important, since those root parameters are supposed to be an image of the $\mu A B F C$ itself, whatever the environment it is in.

\subsection{Measurements description}


Measurements were made by N. Karst at the CEA Liten. He mounted the $\mu$ ABFC on a heating support, in order to control its temperature $T_{F C}$, and he put it in a climatic chamber, aiming at controlling $\left(R H_{a}, T_{a}\right)$. For more details on the experimental set up, please refer to [30].

He settled 8 conditions (Tab.3), and at each condition, he plotted the steady state U-I polarization curve (Fig.5,6). At the end of each stabilized point, he carried out an EIS, which gives $R_{\text {elec. }}$.

As far as the contact surface between the $\mu \mathrm{ABFC}$ chip and its heating support is very small, due to the presence of the $\mathrm{H}_{2}$ chamber underneath it, and as the $\mathrm{H}_{2}$ was in circulating mode, we assumed that the real temperature of the $\mu \mathrm{ABFC} T_{F C}$ could deviate from the theoretically set temperature $T_{F C}^{t h}$, due to this small exchange surface, and to the thermal losses of the $\mu \mathrm{ABFC}$. We then injected a thermal resistance in the model, aiming at representing these variations:

$$
T_{F C}=T_{F C}^{t h}+R_{t h}\left(V_{r e v}-V_{F C}\right) I_{F C}
$$

In those conditions, we have a $T_{F C}^{\text {th }}=30^{\circ} \mathrm{C}$ theoretical temperature, which corresponds to a good operating temperature for the $\mu \mathrm{ABFC}$ (the ideal one being generally $35^{\circ} \mathrm{C}$ ). As a benchmark, $25^{\circ} \mathrm{C}$ is the lower limit for the $\mu \mathrm{ABFC}$ to operate correctly. $45^{\circ} \mathrm{C}$ is quite high for the $\mu \mathrm{ABFC}$ : it generally does not work passed $50^{\circ} \mathrm{C}$. Moreover, a $0.1 R H_{a}$ corresponds to a very dry atmosphere (leading to a high evaporation rate). $R H_{a}=0.7$ corresponds to a not excessively but yet quite humid atmosphere, being able to provoke a lack of evaporation from the cathode, leading to a flooding of the $\mu$ ABFC.

By observing Fig.5 and Fig.6, we can already define some points for the model to respect:

-At $[0.7,30]$, the fuel cell voltage decreases quickly with the current, regarding the other curves: at those humid conditions, the evaporation is not favoured; we could reasonably interpret this as a flooding. This should be traduced in the model by a high $\mathrm{O}_{2}$ diffusion overpotential.

-At $[0.1,45]$, the fuel cell voltage also decreases quickly with the current. The dryness of the conditions would point at a drying out issue. The model should traduce it with a high protonic diffusion overpotential.

\subsection{Model results and discussion}

\subsubsection{The model's global behaviour}

Fig.5 and Fig. 6 show how the model behaves. The parameters we identified are summed up in Tab.4. Fig.7.a,b,c,d and Fig.8.a,b,c,d detail the evolution with current of the overpotentials we defined in our model. The model globally predicts the $\mu$ ABFC's behaviour very well. Nevertheless, some particularities have to be underlined.

The $[0.7,30]$ simulated curve in Fig. 5 shows a problem at high currents. This is due to the $\mathrm{O}_{2}$ diffusion loss, as seen in Fig.7.a. This particular high current variation is directly due to the $R_{D C}$ dependence on temperature, showing that this point has to be improved.

On most of the $30^{\circ} \mathrm{C}$ curves, the low current slope of the simulation does not match the measure. This is also a point to improve, we will propose some explanations in the following (it is probably linked to the non dependency of $I_{0}^{\max }$ on $s$, or from our protonic diffusion model).

Nevertheless, the model is rather accurate. It traduces correctly the influence water should have on the fuel cell. At $[0.7,30]$, which is the more humid condition, Fig.7.a shows that $\mathrm{O}_{2}$ diffusion is the cause of the voltage drop, when the protonic diffusion overpotential is very low; which is logical, the experimental conditions pointing at flooding issues. At $30{ }^{\circ} \mathrm{C}$, as $R H_{a}$ decreases, protonic diffusion becomes more problematic, especially at low currents (a few water is produced, sremains small), as $\mathrm{O}_{2}$ diffuses more easily (Fig.7.a to Fig.7.d).

At $45^{\circ} \mathrm{C}$ (Fig.8.a,b,c,d), where the $\mu$ ABFC is supposed to suffer from further dehydration, protonic diffusion is indeed globally higher than it is at $30^{\circ} \mathrm{C}$, whereas the $\mathrm{O}_{2}$ diffusion overpotential is globally smaller. This last one becomes negligible at $R H_{a}=0.1$ and 0.3 , conditions for which the protonic diffusion becomes very problematic and majoritary compared with the gaseous diffusion problems.

Moreover, the activation losses in each experimental condition are largely predominant compared with the other losses, which is a classical result.

Finally, the electric overpotential $\eta_{\text {elec }}$ is also quite high. It increases with $T_{F C}$, which is not what we could expect, regarding the fact that the protonic conductivity is supposed to be better when the temperature increases. This points at the fact that the evaporation process, which is stronger at higher temperatures, contributes to drying the Nafion out, leading to a lowering of its conductivity. This is confirmed by the fact that $\eta_{\text {elec }}$ rises when $R H_{a}$ decreases.

This behaviour analysis shows that the calculated overpotentials, taken individually, qualitatively illustrate the hydric behaviour we expected, and are quantitatively very plausible.

\subsubsection{Discussion around the parameters}

Every optimized parameter is in a classic range regarding the literature. Moreover, we almost succeeded in identifying a unique set of parameters valid for a large range of experimental conditions. We had to adapt only two parameters according to temperature (Tab.4): $I_{0}^{\max }$ and $D_{H^{+}, 0}$, which can potentially traduce problems in our model. Nevertheless, we can propose some explanations. 


\section{Discussion for $D_{H^{+}, 0}$ :}

This can be a collateral effect of the problem we have on $I_{0}^{\max }$. Nevertheless, the $s$ dependency exposed in Eq.47 could be the cause of the problem. Further investigations, proposed in the conclusion part, could bring more precise elements on this. This problem on $D_{H^{+}, 0}$ is probably responsible for the wrong slope of the model curves Fig.5 and

Fig.6 at low current values, even if this point could also be corrected by a $I_{0}^{\max }$ dependency to $s$.

Discussion for $I_{0}^{\max }$ :

In our extractions, $I_{0}^{\max }\left(30^{\circ} \mathrm{C}\right)>I_{0}^{\max }\left(45^{\circ} \mathrm{C}\right)$, more precisely:

$$
I_{0}^{\max }\left(30^{\circ} \mathrm{C}\right)=10 . I_{0}^{\max }\left(45^{\circ} \mathrm{C}\right)
$$

Even if Eq.34 is not perfect, we should at least expect $I_{0}^{\max }\left(30^{\circ} \mathrm{C}\right)<I_{0}^{\max }\left(45^{\circ} \mathrm{C}\right)$, as far as the equivalent exchange current should rise with a temperature elevation. Our temperature dependency, even if it could be improved, is not the source of the problem. There remain two possible explanations to this. Maybe this gap is caused by a hedge somewhere else in the model, for example on protonic diffusion, which remains uncertain. But it can also point at the need for $I_{0}^{\max }$ to depend on $s$, like it is often done in the literature $[4,5,9,11,35]$. Nevertheless, all those studies use relations of the following form:

$$
I_{0}^{\max }=I_{0}^{\max , 0}(1-s)^{b_{a c t}}
$$

Where $b_{a c t}$ often equals 1 (nevertheless, $b_{a c t}=2$ in [35], and $b_{a c t}=1,2,5,8$ is explored in [9]). This traduces the fact that the active surface can only be reduced by a flooding effect. This can be explained by the fact that it is very hard to observe drying out issues on classical 'closed' fuel cells, which is absolutely not the case with $\mu$ ABFC.

In our case, at $45^{\circ} \mathrm{C}$, our simulations (Fig.3), and the Relec measures (Fig.4), tend to show that the $\mu \mathrm{ABFC}$ is globally drier than it is at $30^{\circ} \mathrm{C}$, that is to say that on average, $s\left(30^{\circ} \mathrm{C}\right)>s\left(45^{\circ} \mathrm{C}\right)$. This means that a Eq.51 type relation would not be sufficient. We need another relation to traduce the fact that if the cathode is too dry, it also loses active surface (no departure/arrival possible for protons from/to the active sites). For example:

$$
I_{0}^{\max }=I_{0}^{\max , 0}(s(1-s))^{b_{a c t}}
$$

\section{Conclusions and perspectives}

We developed a full macroscopic steady state physical model for the $\mu \mathrm{ABFC}$, that takes into account the influence of atmospheric conditions on its behaviour. It is able to predict if the $\mu A B F C$ will suffer from drying out or from flooding, and can tell what condition would be the best for the fuel cell's performances.

Nevertheless, some points need to be improved. The convection diffusion model of the atmosphere is probably too minimalist. Some other parts need further investigation, like the influence of the cathodic water content on the equivalent exchange current $I_{0}^{\max }$, or on the protonic diffusion.

Full EIS that were carried out all along the measurements we used remain partially unanalysed. This could be a good starting point to adjust our model. Indeed, studying the spectra and their evolution with the water content could help us to refine our $s$ depending laws, particularly for the protonic diffusion. This phenomenon clearly appears indeed in the EIS results. This analysis would also be very helpful concerning the distinction and the quantification of each phenomenon's influence.

The next step will be to connect this model to the model of the atmosphere inside the packaging the $\mu A B F C$ will be set in. The aim will be to know how to drive the packaging's auxiliaries (fans) in order to settle the best atmosphere for the $\mu A B F C$.

\section{Acknowledgments}

This work was supported by STMicroelectronics Tours (France), and the LAPLACE Laboratory, Toulouse (France). We are grateful to Nicolas Karst, who performed the helpful measurements we used for our model.

\section{References}

1. Jin Hyun Nam, Kyu-Jin Lee, Gi-Suk Hwang, Charn-Jung Kim, Massoud Kaviany, Int. J. Heat and Mass Transfer 52 (2009) $2779-$ 2791

2. Qiangu Yan, Hossein Toghiani, Junxiao Wu, J. Power Sources 158 (2006) 316-325

3. Nicolas Karst, Vincent Faucheux, Audrey Martinent, Pierre Bouillon,

Jean-Yves Laurent, Florence Druart, Jean-Pierre Simonato, J. Power Sources 195 (2010) 1156-1162

4. Z.H. Wang, C.Y. Wang, K.S. Chen, J. Power Sources 94 (2001) 40-50

5. Min-Hsing Chang, Falin Chen, Hong-She Teng, J. Power Sources 160 (2006) 268-276

6. Lixin You, Hongtan Liu, Int. J. Heat and Mass Transfer 45 (2002) 2277-2287

7. Qianpu Wang, Michael Eikerling, Datong Song, Zhong-Sheng Liu, J.Electrochem. Soc., 154 (6) F95-F101 (2007)

8. Luis Matamoros, Dieter Brüggemann, J. Power Sources 161 (2006) 203-213

9. Prodip K. Das, Xianguo Li, Zhong-Sheng Liu, Int. J. Hydrogen energy 35 ( 2010) $2403-2416$ 
10. Yun Wang, Xuhui Feng, J. Electrochem. Soc., 155 (12) B1289-B1295 (2008)

11. Yun Wang, Xuhui Feng, J. Electrochem. Soc., 156 (3) B403-B409 (2009)

12. M.G. Santarelli, M.F. Torchio and P. Cochis, J. Power Sources 159 (2006), p. 824

13. Kui Jiao, Xianguo Li, Int. J. hydrogen energy 34 ( 2009 ) 8171-8184

14. T. Berning and N. Djilali, J. Electrochem. Soc., 150 (12) A1589-A1598 (2003)

15. Nikhil H. Jalani, Pyoungho Choi, Ravindra Datta, J. Membrane Science 254 (2005) 31-38

16. Igor Nazarov, Keith Promislow, J. Electrochem. Soc., 154 (7) B623-B630 (2007)

17. Pyoungho Choi and Ravindra Datta, J. Electrochem. Soc., 150 (12) E601-E607 (2003)

18. Qiangu Yan, Hossein Toghiani, Junxiao Wu, J. Power Sources 158 (2006) 316-325

9. Paul Majsztrik, Andrew Bocarsly, and Jay Benziger, J. Phys. Chem. B 2008, 112, 16280-16289

20. X. Liu, H. Guo, F. Ye and C.F. Ma, Electrochim. Acta 52 (2007), p. 3607

21. X. Liu, H. Guo, F. Ye and C.F. Ma, J. Power Sources 156 (2006), p. 267

22. Klaus Tüber, David Pócza, Christopher Hebling, J. Power Sources 124 (2003) 403-414

23. Yongtaek Lee, Bosung Kim, Yongchan Kim, Int. J. Hydrogen Energy 34 (2009) 7768-7779

24. A. Turhan, K. Heller, J.S. Brenizer, M.M. Mench, J. Power Sources 160 (2006) 1195-1203.

25. J. Zhang, D. Kramer, R. Shimoi, Y. Ono, E. Lehmann, A. Wokaun, K. Shinohara and G. Scherer, Electrochem. Acta 51 (2006), pp. 2715-2727

26. J. St-Pierre, J. Electrochem. Soc. 154 (2007), p. B724.

27. Yong-Song Chen, Huei Peng, J. Power Sources 185 (2008) 1179-1192

28. Gang Luo, Hyunchul Ju, Chao-Yang Wang, J.Electrochemical Society, 154 (3) B316-B321 (2007)

29. Nicolas Karst, Vincent Faucheux, Audrey Martinent, Pierre Bouillon, Jean-Yves Laurent, Florence Druart, Jean-Pierre Simonato,

J. Power Sources 195 (2010) 1156-1162

30. Nicolas Karst, Ph.D. Thesis, ST Microelectronics, CEA Liten, (2009), p75-80

31. T. E. Springer, T. A. Zawodzinski, and S. Gottesfeld, J. Electrochem. Soc., Vol. 138, No. 8, August 1991

32. Yong-Song Chen, Huei Peng, J. Power Sources 185 (2008) 1179-1192

33. Cecile Gondrand, Ph.D Thesis, (2006), INPT

34. Frédéric Debaste, Ph.D Thesis, (2008), ULB, (chap7, p99-103)

35. Tony Thampan, Sanjiv Malhotra, Hao Tang, Ravindra Datta, J. Electrochem. Soc., 147 (9) 3242-3250 (2000)

35. Gang Luo, Hyunchul Ju, Chao-Yang Wang, J.Electrochemical Society, 154 (3) B316-B321 (2007)

36. Yun Wang, Xuhui Feng, Journal of The Electrochemical Society, 156 (3) B403-B409 (2009)

37. N. Yousfi-Steiner, Ph. Moçotéguy, D. Candusso, D. Hissel, A. Hernandez, A. Aslanides, J. Power Sources 183 (2008) 260-274

38. Jin Hyun Nam, Massoud Kaviany, Int. J. Heat and MassTransfer 46 (2003) 4595-4611

39. M.M. Mezedur, M. Kaviany, W. Moore, AIChE J. 48 (2002) 15-24

40. René Lefebvre, lesson, Ecoulement Multiphase en milieu poreux, (2003), INRS (UQ), chap4, p145. 
Fig.1. Photography of an non assembled $\mu A B F C$

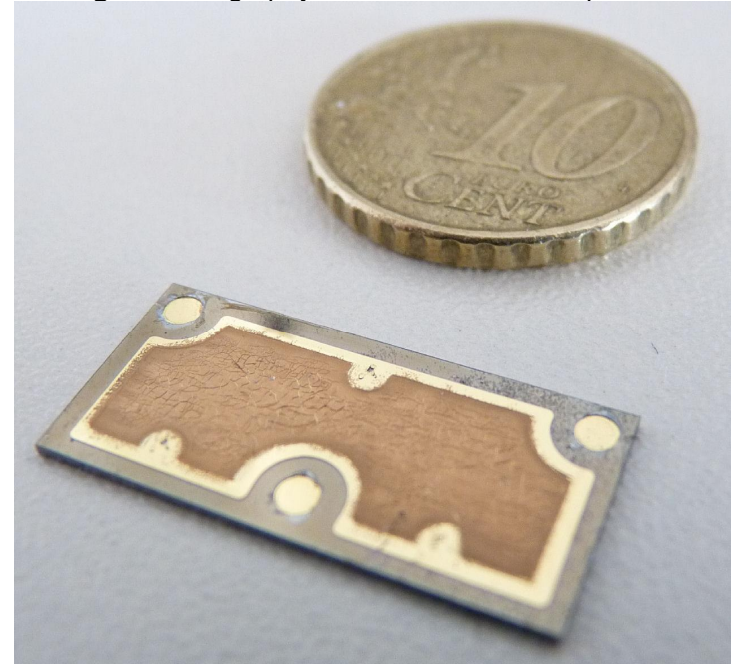

Fig.2. Schematic cross-section the $\mu A B F C$

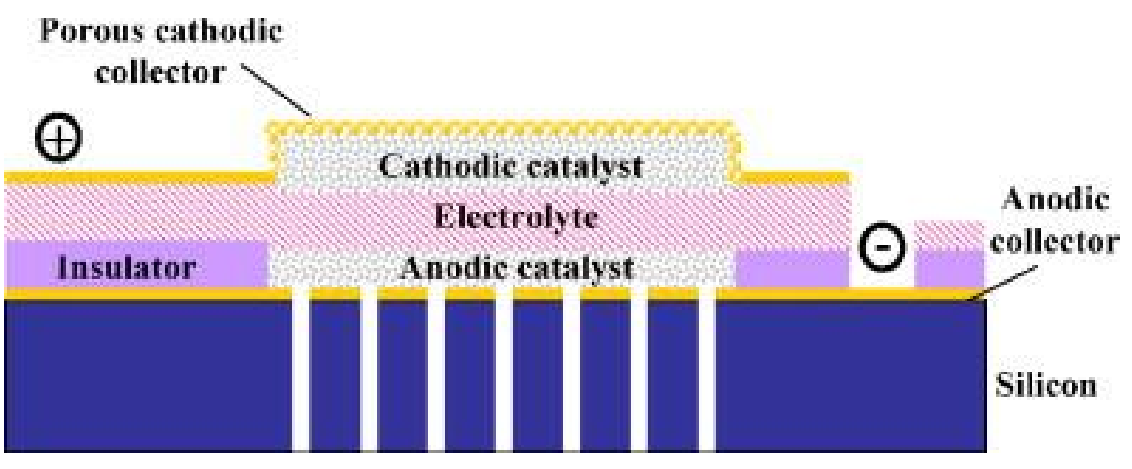


Fig.3. Simulation of the saturation dependency on $I_{F C}$ for the Tab.3 experimental conditions and with the Tab.4 parameters
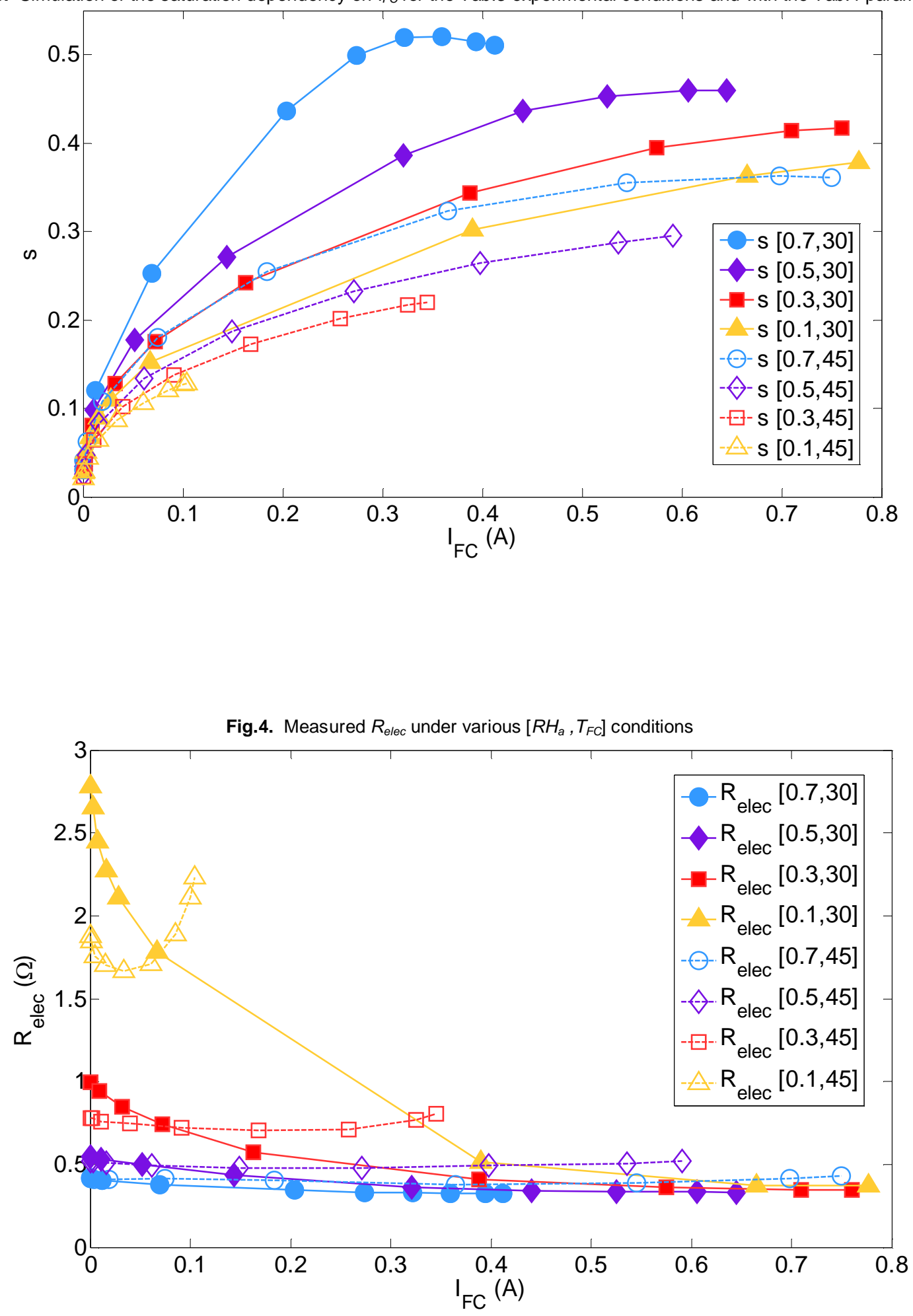

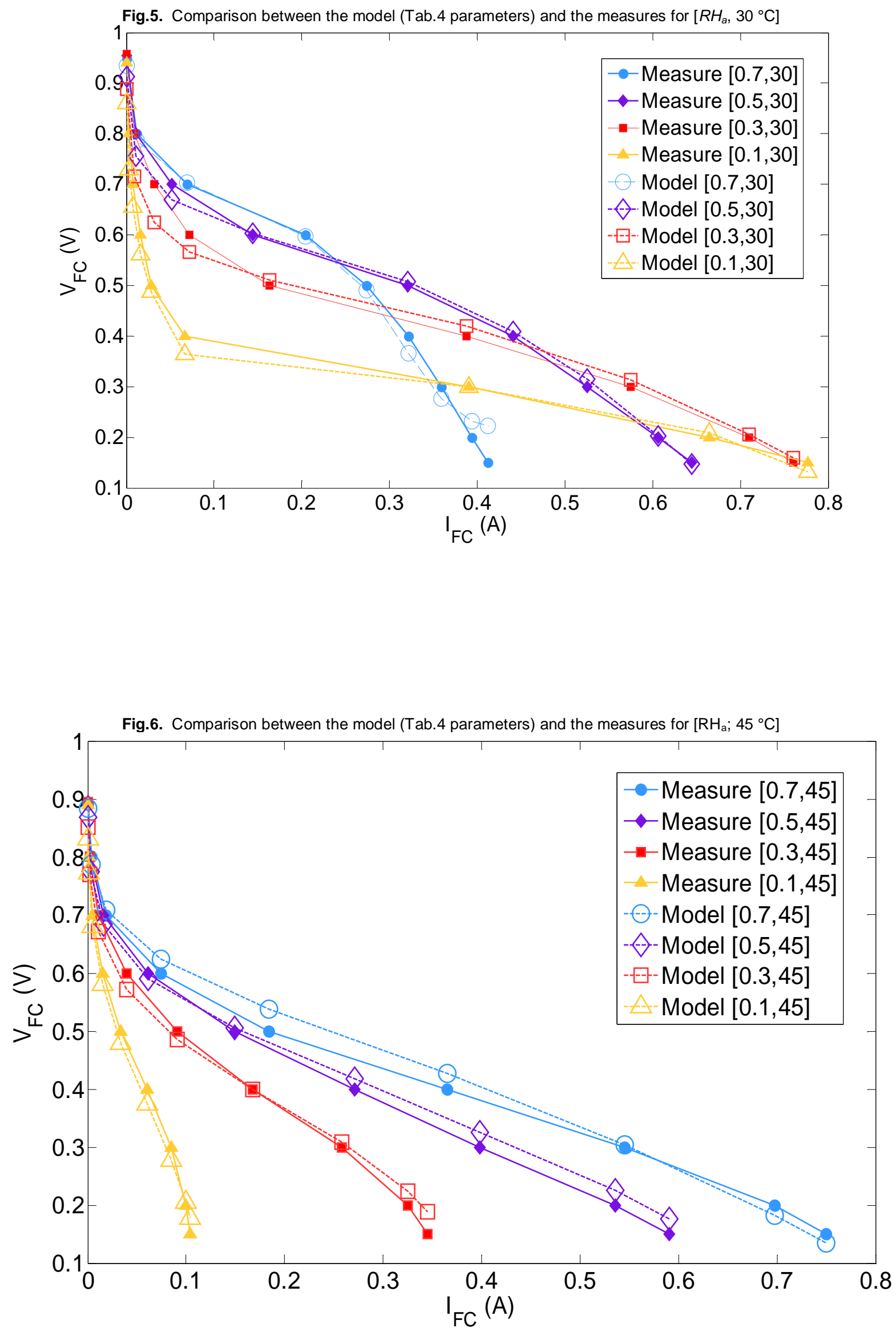
Fig.7.a,b,c,d. Simulated (Tab.4 parameters) overpotentials $(\mathrm{V})$ for $30^{\circ} \mathrm{C}$, respectively for $R H_{a}=0.7,0.5,0.3,0.1$, depending on $I_{F C}(\mathrm{~A})$
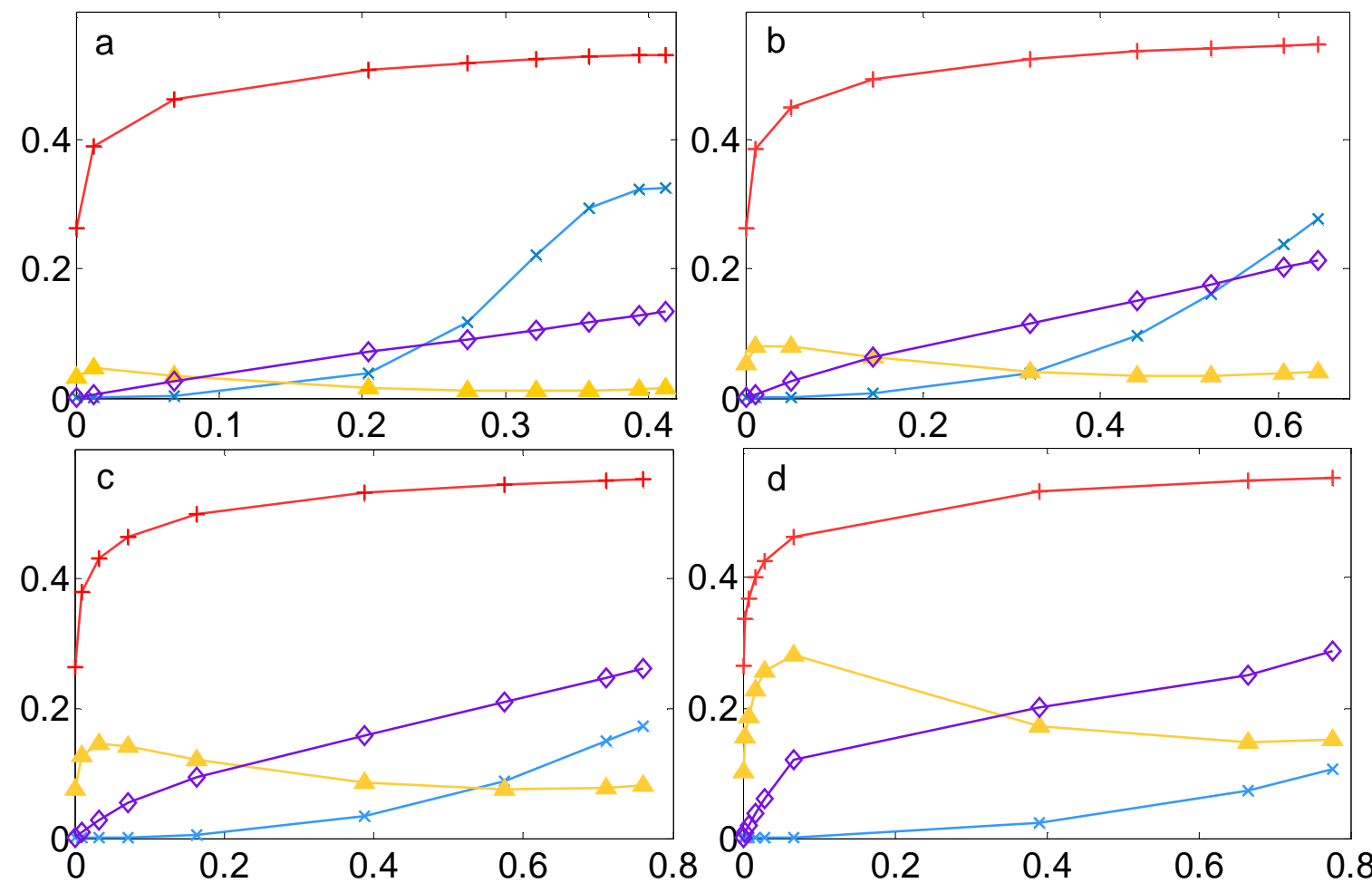

$+\eta_{\text {act }} * \eta_{\text {Diff }}^{\mathrm{O}}-\eta_{\text {Diff }}^{\mathrm{H}^{+}} \diamond \eta_{\text {Elec }}$

Fig.8.a,b,c,d. Simulated (Tab.4 parameters) overpotentials $(\mathrm{V})$ for $45^{\circ} \mathrm{C}$, respectively for $R H_{a}=0.7,0.5,0.3,0.1$, depending on $I_{F C}(\mathrm{~A})$.
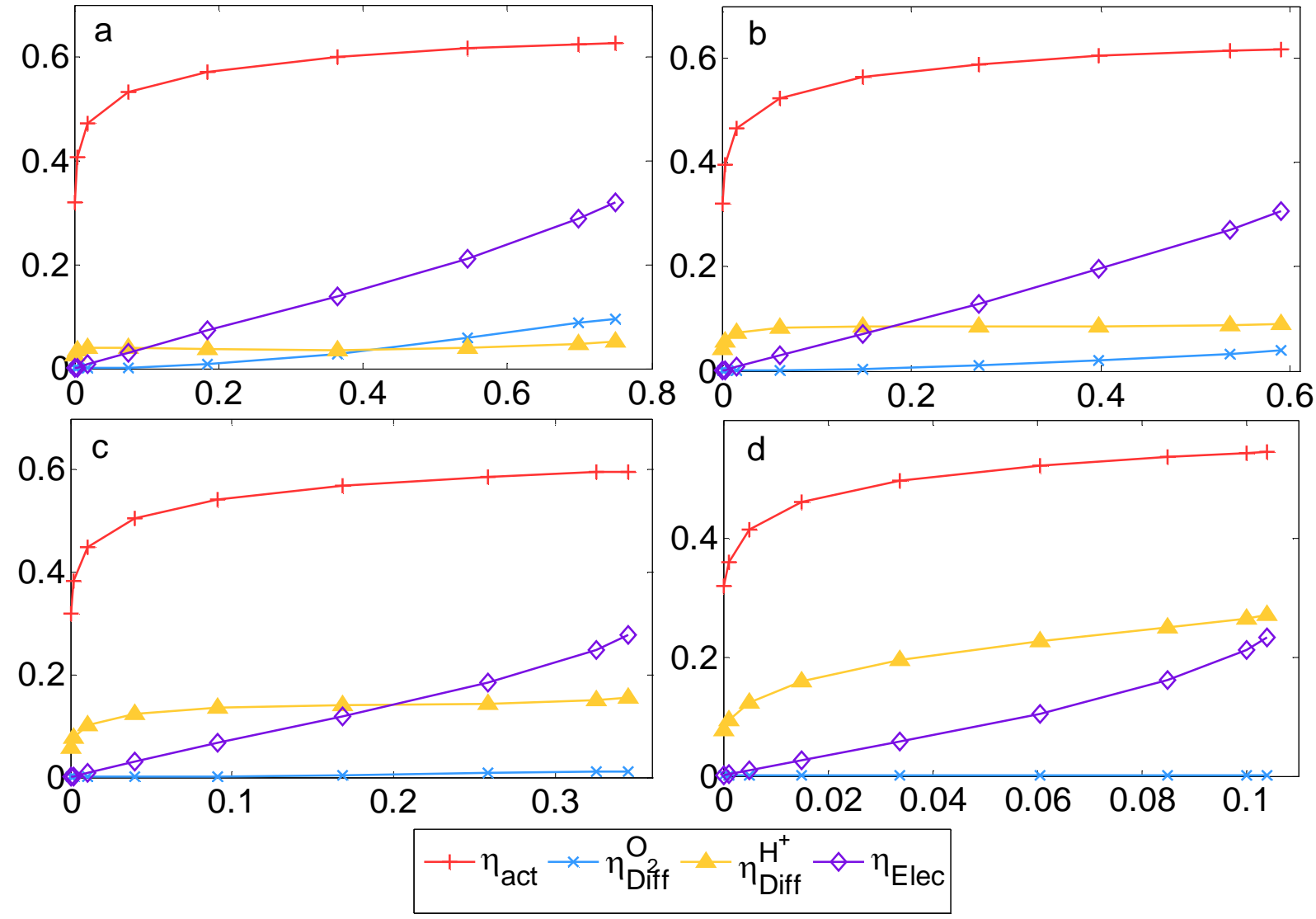
Table.1. Overview of possible literature values for $b_{X}$

\begin{tabular}{|l|l|}
\hline References & $b_{X}$ \\
\hline$[1,7,8,40]$ & 1.5 \\
\hline$[4,5,6,27,40]$ & 1 \\
\hline$[1,38,40]$ & 2 \\
\hline$[39]$ & 0.71 \\
\hline$[40]$ & 4 \\
\hline$[40]$ & 3.33 \\
\hline$[40]$ & 1.67 \\
\hline
\end{tabular}

Table.2. Definition of the tuning parameters of the model

\begin{tabular}{|c|c|c|c|}
\hline Phenomenon & Parameters & Name & units \\
\hline \multirow{5}{*}{ Evaporation } & $\chi$ & Mass transfer coefficient & $\mathrm{m}^{3} \cdot \mathrm{s}^{-1}$ \\
\hline & $R_{\text {diff }, 0}^{a}$ & $\begin{array}{l}\text { Diffusion resistance in the atmosphere at } \\
298 \mathrm{~K}\end{array}$ & s.m $\mathrm{m}^{-3}$ \\
\hline & $a_{\mathrm{H}_{2} \mathrm{O}}=a_{\mathrm{H}^{+}}=a_{\mathrm{O}_{2}}$ & Porosity correction coefficient & $\varnothing$ \\
\hline & $b_{\mathrm{H}_{2} \mathrm{O}}$ & $\begin{array}{l}\mathrm{H}_{2} \mathrm{O} \text { sensitivity to water presence } \\
\text { coefficient }\end{array}$ & $\varnothing$ \\
\hline & $D_{\mathrm{H}_{2} \mathrm{O}, 0}$ & Diffusivity of gaseous $\mathrm{H}_{2} \mathrm{O}$ in air at $298 \mathrm{~K}$ & $m^{2} \cdot s^{-1}$ \\
\hline \multirow[b]{2}{*}{ Activation } & $\alpha$ & Equivalent transfer coefficient & $\varnothing$ \\
\hline & $I_{0}^{\max }$ & Maximal exchange current & A \\
\hline \multirow{3}{*}{$\mathrm{O}_{2}$ diffusion } & $D_{O_{2}, 0}$ & Diffusivity of $\mathrm{O}_{2}$ in air at $298 \mathrm{~K}$ & $m^{2} \cdot s^{-1}$ \\
\hline & $b_{O_{2}}$ & $\mathrm{O}_{2}$ sensitivity water presence coefficient & $\varnothing$ \\
\hline & $\beta_{O_{2}}$ & $\mathrm{O}_{2}$ corrected transfer coefficient & $\varnothing$ \\
\hline \multirow{3}{*}{$\mathrm{H}^{+}$diffusion } & $D_{H^{+}, 0}$ & Diffusivity of $\mathrm{H}^{+}$in water at $298 \mathrm{~K}$ & $m^{2} \cdot s^{-1}$ \\
\hline & $b_{H^{+}}$ & $\begin{array}{l}\mathrm{H}^{+} \text {sensitivity to water presence } \\
\text { coefficient }\end{array}$ & $\varnothing$ \\
\hline & $\beta_{H^{+}}$ & $\mathrm{H}^{+}$corrected transfer coefficient & $\varnothing$ \\
\hline Crossover & $I_{n}$ & Equivalent leak current & A \\
\hline Heat transfer to the $\mu \mathrm{ABFC}$ & $R_{t h}$ & Heat transfert resistance & $\mathrm{K} . \mathrm{W}^{-1}$ \\
\hline
\end{tabular}

Table.3. Experimental conditions

\begin{tabular}{|l|l|l|l|l|}
\hline$T_{F C}^{t h}=T_{a}$ & \multicolumn{4}{|l|}{$R H_{a}$} \\
\hline $45^{\circ} \mathrm{C}$ & 0.1 & 0.3 & 0.5 & 0.7 \\
\hline $30^{\circ} \mathrm{C}$ & 0.1 & 0.3 & 0.5 & 0.7 \\
\hline
\end{tabular}


Table.4. The extracted parameters for the model

\begin{tabular}{|c|c|c|c|c|}
\hline Phenomenon & Parameters & $30^{\circ} \mathrm{C}$ & $45^{\circ} \mathrm{C}$ & units \\
\hline & $\chi$ & \multicolumn{2}{|l|}{$1.1 * 10^{-5}$} & $\mathrm{~m}^{3} \cdot \mathrm{s}^{-1}$ \\
\hline & $R_{\text {diff }, 0}^{a}$ & \multicolumn{2}{|l|}{$2^{*} 10^{6}$} & $\mathrm{~s} . \mathrm{m}^{-3}$ \\
\hline \multirow{3}{*}{ Evaporation } & $a_{H_{2} O}=a_{H^{*}}=a_{O_{2}}$ & \multicolumn{2}{|l|}{1.5} & $\varnothing$ \\
\hline & $b_{\mathrm{H}_{2} \mathrm{O}}$ & \multicolumn{2}{|l|}{2.7} & $\varnothing$ \\
\hline & $D_{\mathrm{H}_{2} \mathrm{O}, 0}$ & \multicolumn{2}{|l|}{$5 * 10^{-5}$} & $\mathrm{~m}^{2} \cdot \mathrm{s}^{-1}$ \\
\hline \multirow[b]{2}{*}{ Activation } & $\alpha$ & \multicolumn{2}{|l|}{0.3} & $\varnothing$ \\
\hline & $I_{0}^{\max }$ & $1 * 10^{-4}$ & $1 * 10^{-5}$ & A \\
\hline \multirow{3}{*}{$\mathrm{O}_{2}$ diffusion } & $D_{O_{2}, 0}$ & \multicolumn{2}{|l|}{$1.6^{*} 10^{-5}$} & $\mathrm{~m}^{2} \cdot \mathrm{s}^{-1}$ \\
\hline & $b_{O_{2}}$ & \multicolumn{2}{|l|}{5} & $\varnothing$ \\
\hline & $\beta_{O_{2}}$ & \multicolumn{2}{|l|}{0.08} & $\varnothing$ \\
\hline \multirow{3}{*}{$\mathrm{H}^{+}$diffusion } & $D_{H^{+}, 0}$ & $2.5^{*} 10^{-1}$ & $5.7^{*} 10^{-1}$ & $\mathrm{~m}^{2} \cdot \mathrm{s}^{-1}$ \\
\hline & $b_{H^{+}}$ & \multicolumn{2}{|l|}{2.2} & $\varnothing$ \\
\hline & $\beta_{H^{+}}$ & \multicolumn{2}{|l|}{0.1} & $\varnothing$ \\
\hline Crossover & $I_{n}$ & \multicolumn{2}{|l|}{$7^{*} 10^{-4}$} & A \\
\hline $\begin{array}{l}\text { Heat transfer } \\
\text { to the } \mu \text { ABFC }\end{array}$ & $R_{t h}$ & \multicolumn{2}{|l|}{8.1} & $\mathrm{~K}^{2} \mathrm{~W}^{-1}$ \\
\hline
\end{tabular}

Table.5. Some other values used for the model

\begin{tabular}{|l|l|l|l|}
\hline Quantity & Name & Value & units \\
\hline$C_{H^{+}}^{r e f}$ & Reference concentration on protons [7] & 200 & $\mathrm{~mol} . \mathrm{m}^{-3}$ \\
\hline$\delta_{K}$ & Reference internal diffusion length & $1.5^{\star} 10^{5}$ & $\mathrm{~m}$ \\
\hline$S_{K}$ & Reference internal diffusion surface & $4^{*} 10^{-5}$ & $\mathrm{~m}^{2}$ \\
\hline$\varepsilon$ & Cathodic porosity [30] & 0.4 & $\varnothing$ \\
\hline$P_{H_{2}}$ & $\mathrm{H}_{2}$ partial pressure & 1 & $\mathrm{bar}$ \\
\hline$P_{O_{2}}$ & O $_{2}$ atmospheric partial pressure & 0.2 & $\mathrm{bar}$ \\
\hline$\Delta G^{0}$ & Standard Gibbs energy & 236309 & $\mathrm{~J} . \mathrm{mol}^{-1}$ \\
\hline$R$ & Universal gas constant & 8.314 & $\mathrm{~J} . \mathrm{mol}^{-1} \cdot \mathrm{K}$ \\
\hline$F$ & Faraday's constant & 96485 & $\mathrm{C}$ \\
\hline
\end{tabular}

